\title{
Effects of Drying-Rewetting Frequency on Vertical and Lateral Loss of Soil Organic Carbon in a Tidal Salt Marsh
}

\author{
Juanyong $\mathrm{Li}^{1,2,3} \cdot$ Wendi Qu ${ }^{1,2,3} \cdot$ Guangxuan $\mathrm{Han}^{1,3} \cdot$ Feng $\mathrm{Lu}^{4} \cdot$ Yingfeng Zhou ${ }^{4} \cdot$ Weimin Song ${ }^{1,3} \cdot$ Baohua Xie ${ }^{1,3}$. \\ Franziska Eller ${ }^{5}$
}

Received: 29 October 2019 / Accepted: 6 March 2020

(C) Society of Wetland Scientists 2020

\begin{abstract}
Tidal salt marshes, as "blue carbon" ecosystems, play a critical role in mitigation of global climate change since their large soil organic carbon (SOC) pool. Drying-rewetting cycles induced by periodic tides have profound influence on soil carbon cycling in tidal salt marshes. However, the magnitude and mechaanism of the effects of drying-rewetting frequency on SOC loss in tidal salt marshes is still uncertain. Here, we conducted a mesocosm experiment to identify how drying-rewetting frequency changes alter the vertical $\left(\mathrm{CO}_{2}\right.$ and $\left.\mathrm{CH}_{4}\right)$ and lateral (dissolved organic carbon) carbon losses of soils in a tidal salt marsh in the Yellow River Delta (YRD). We found that increasing soil moisture inhibited $\mathrm{CO}_{2}$ emission but stimulated $\mathrm{CH}_{4}$ emission in a tidal salt marsh. Soil dissolved organic carbon (DOC) was produced in the drying phase and rewetting lead to the loss of DOC. Soil moisture and salinity change induced by drying-rewetting cycles were the critical factors controlling vertical organic carbon loss in a tidal salt marsh. DOC had significant effects on $\mathrm{CO}_{2}$ emissions. Changes of tidal action and drying-rewetting cycle induced by global change can affect the pathway of carbon loss in a tidal salt marsh.
\end{abstract}

Keywords Tidal salt marshes $\cdot$ Drying-rewetting cycle $\cdot \mathrm{CO}_{2}$ and $\mathrm{CH}_{4}$ emissions $\cdot$ Dissolved organic carbon

\section{Introduction}

Tidal salt marshes have been termed as one of the most important "blue carbon" ecosystems. They are efficient in sedimentation and trapping associated soil organic carbon (SOC)

Guangxuan Han

gxhan@yic.ac.cn

1 CAS Key Laboratory of Coastal Environmental Processes and Ecological Remediation, Yantai Institute of Coastal Zone Research (YIC), Shandong Key Laboratory of Coastal Environmental Processes, YICCAS, Chinese Academy of Sciences (CAS), Yantai, Shandong 264003, People's Republic of China

2 University of Chinese Academy of Sciences, Beijing 100049, People's Republic of China

3 Center for Ocean Mega-Science, Chinese Academy of Sciences, 7 Nanhai Road, Qingdao 266071, People's Republic of China

4 Administration Committee of the Yellow River Delta National Nature Reserve, Dongying, Shandong 257500, People's Republic of China

5 Department of Bioscience, Aarhus University, Ole Worms Alle 1, DK-8000 Aarhus C, Denmark during tidal inundation (McLeod et al. 2011). Though the global area is much smaller than other types of ecosystem, e.g., forest or grassland, the carbon sequestration rates of "blue carbon" ecosystems are much greater than those of terrestrial ecosystems (McLeod et al. 2011; Lovelock et al. 2017; Ouyang et al. 2017). Carbon can be sequestered in salt marshes at a rate nearly 40 times higher than that in tropical rainforests (Duarte et al. 2005). Accordingly, "blue carbon" ecosystems, in particular tidal salt marshes, are critical for the global carbon cycle and the mitigation of climate change, which is noteworthy in the future (Howard et al. 2017; Macreadie et al. 2017).

The tidal salt marsh serves not only as a long-term carbon sink, but as a potential carbon source once the ecosystem is lost or degraded (Fellman et al. 2017; Howard et al. 2017; Lovelock et al. 2017; Macreadie et al. 2017). There exist two pathways for carbon loss in tidal salt marshes, namely vertical and lateral carbon loss (Evans et al. 2015; Fellman et al. 2017). Vertical carbon loss, including $\mathrm{CO}_{2}$ and $\mathrm{CH}_{4}$ emissions, is generally considered as a major contributor to soil carbon loss of terrestrial ecosystems (Liu et al. 2017). However, lateral carbon loss of tidal salt marsh obviously cannot be ignored because of regularly tidally flooding and 
scouring effect of periodical tides (Maher et al. 2013; Howard et al. 2017). Dissolved organic carbon (DOC) is recognized as one of the dominant forms of lateral carbon loss from terrestrial ecosystems to aquatic ecosystems (Billett et al. 2010; D'Amore et al. 2015). Besides, as a labile component of SOC, DOC is still found to have a close correlation with soil carbonic greenhouse gas formations (Fellman et al. 2017; Liu et al. 2017; Lee et al. 2018; Qu et al. 2018). Thus, both lateral and vertical carbon loss from tidal salt marshes soil to ocean and atmosphere, respectively, should be considered into "blue carbon" loss of salt marshes.

Drying-rewetting cycle and its induced surface accumulation and leaching of salt are considered the most prominent characteristics differentiating the tidal salt marsh from other wetland ecosystems (Chambers et al. 2013). In recent years, tidal salt marshes have been seriously disturbed or even damaged by many anthropogenic and natural factors (Kirwan and Megonigal 2013; Tian et al. 2016), including sea level rise (IPCC 2014), dam construction (Kirwan and Megonigal 2013), and invasions of exotic plants (Yuan et al. 2015), which lead to the changes in soil drying-rewetting frequency of tidal salt marsh (Morillas et al. 2015). Changes in drying-rewetting frequency can affect soil SOC loss through influencing soil moisture, salinity and other physio-chemical properties, and the microbial activity. In general, drying always produced positive effects on $\mathrm{CO}_{2}$ production and negative effects on $\mathrm{CH}_{4}$ formation because of the aerobic conditions in wetlands (Olsson et al. 2015; Liu et al. 2017). Moreover, decomposition of SOC always fluctuate with soil drying-rewetting cycles, because that the microbes always respond quickly to the changes of soil moisture and salinity during drying-rewetting cycles (Moyano et al. 2013; Yemadje et al. 2016). For instance, Birch Effect always observed with a rewetting event after extreme drying as a result of rapid excitation of microbial activity (Birch 1958; Mavi and Marschner 2012). In fact, the increase in salinity usually reduces SOC loss as salinity negatively affects soil microbial activity (Chambers et al. 2013). However, some other studies showed that an increase in salinity can promote soil respiration by generating cellular osmotic stress (Saviozzi et al. 2011; Drake et al. 2014). In addition, drying-rewetting also leads to a release of DOC, as a result of the weakened protective effect to SOC from soil aggregates. Furthermore, the drier the soil, the more DOC would be released after rewetting (Xiang et al. 2008; Gaelen et al. 2014). However, for these previous experiments were mostly concentrated on the effects of drying-rewetting cycles on arid ecosystems, the effects on SOC loss in tidal saltmarshes is still not clear.

The Yellow River Delta (YRD) is one of the world's most active and the youngest coastal wetland, which is affected by land-ocean interactions (Qin et al. 2010; Han et al. 2014). Salt marsh in the YRD, a newly formed coastal wetland, held great potential of carbon sequestration, yet it also can be a huge carbon source in the face of changes of hydrodynamics (Ye et al. 2016). Accordingly, the YRD become an ideal area to investigate the effects of drying-rewetting frequency on SOC loss in tidal salt marsh. The aims here were (1) to make the determination of soil vertical $\left(\mathrm{CO}_{2}\right.$ and $\left.\mathrm{CH}_{4}\right)$ and lateral (DOC) carbon loss under different drying-rewetting frequency treatments in tidal salt marsh; (2) to investigate the effects of soil properties on emissions of $\mathrm{CO}_{2}$ and $\mathrm{CH}_{4}$ and DOC production; (3) to demonstrate the effects of varying soil DOC concentration on $\mathrm{CO}_{2}$ and $\mathrm{CH}_{4}$ emissions in this study.

\section{Materials and Methods}

\section{Site Description}

This study was performed using soil from a tidal salt marsh in the YRD $\left(37^{\circ} 35^{\prime}-38^{\circ} 12^{\prime} \mathrm{N}, 118^{\circ} 33^{\prime}-119^{\circ} 20^{\prime} \mathrm{E}\right)$, Shandong, China. It has a warm temperate and continental monsoon climate with distinctive seasons and distributions of rain and heat. The annual average temperature is about $12.9^{\circ} \mathrm{C}$, and the annual average precipitation is about $640 \mathrm{~mm}$ and mainly concentrates in summer (from June to September). According to the flooding characteristics of the tidal flat, the area could be divided into high marsh, middle marsh and low marsh. Tide in low marsh is irregular semidiurnal (twice a day), while the high marsh was affected by tidal flooding twice a month. The mean tidal range from $0.73 \mathrm{~m}$ to $1.77 \mathrm{~m}$. The salinity of sea water ranges from $26 \%$ to $30 \%$ (Song et al. 2013). The marsh soil is largely covered by Fluvo-aquic soil and saline soil (Jia et al. 2017). The chemical and physical properties of topsoil $(0-10 \mathrm{~cm})$ in the salt marsh are listed in Table 1.

\section{Soil Collection and Preparation}

Four $1 \mathrm{~m} \times 1 \mathrm{~m}$ typical quadrats in the Suaeda salsa (S. salsa) marsh in the high marsh in the YRD were selected as the study

Table 1 Soil physio-chemical properties of surface soil in a salt marsh in Yellow River Delta (mean \pm standard error, $n=3$ )

\begin{tabular}{lc}
\hline Parameters & Original soil \\
\hline $\mathrm{pH}$ & $8.66 \pm 0.02$ \\
Salinity $\left(\mathrm{mg} \mathrm{g}^{-1}\right)$ & $14.73 \pm 0.29$ \\
Dissolved organic carbon (DOC) $\left(\mathrm{mg} \mathrm{g}^{-1}\right)$ & $0.03 \pm 0$ \\
Total organic carbon $(\mathrm{TOC})\left(\mathrm{mg} \mathrm{g}^{-1}\right)$ & $2.96 \pm 0.04$ \\
Total carbon (TC) $\left(\mathrm{mg} \mathrm{g}^{-1}\right)$ & $16.04 \pm 0.3$ \\
Total nitrogen (TN) $\left(\mathrm{mg} \mathrm{g}^{-1}\right)$ & $0.34 \pm 0.01$ \\
C: $\mathrm{N}$ ratio $(\mathrm{C} / \mathrm{N})$ & $8.66 \pm 0.41$ \\
Clay fraction $(\%)$ & $6.48 \pm 0.04$ \\
Silt fraction $(\%)$ & $37.66 \pm 0.23$ \\
Sand fraction $(\%)$ & $55.86 \pm 0.21$ \\
\hline
\end{tabular}


sites in September 2017. 90 intact soil cores $(30 \mathrm{~cm}$ tall, $16 \mathrm{~cm}$ diameter) were collected from the four plots by pushing PVC tubes $(50 \mathrm{~cm}$ tall, $16 \mathrm{~cm}$ diameter) into the depth of $30 \mathrm{~cm}$. All the soil cores were collected in two days. All soil cores with PVC tubes were immediately transported to the Yellow River Delta Ecology Research Station of Coastal Wetland, Chinese Academy of Sciences, and plastic base was installed at the bottom of each PVC tube to prevent the loss of soil and water. To ensure consistency, all the soil cores were wet with the same quantity of water and pre-incubated for 5 days before the experiment.

\section{Setup of Mesocosm Experiments}

After pre-incubation, soil cores were immediately incubated for additional 60 days. All soil cores were stratified into two parts: one part was used for gas sampling; the other part was for destructive harvests. In tidal salt marshes in the YRD, low tide flat can be flooded by tidal seawater once a day, while high tide flat can only be flooded approximately once a month (Jia et al. 2017). Besides, some area of tidal salt marshes was turned into dry land and would never be flooded by tide due to the construction of anthropogenic barriers. Therefore, five treatments of drying-rewetting frequency were set to simulate tidal flats with different elevations: (1) CM (constantly moist): the soil cores were watered per day; (2) 5D: twelve cycles of 5-day air drying events, separated by 12 rewetting events; (3) 15D: four cycles of 15day air drying events, separated by 4 rewetting events; (4) 30D: two cycles of 30-day air drying events, separated by two rewetting; (5) $\mathrm{CD}$ (continuously dry): the soil cores were naturally desiccated during the whole incubation. In the drying phase, soil was air dried naturally. At the end of each drying phase, soil cores were rewetted, and the water level was kept at $10 \mathrm{~mm}$ for $8 \mathrm{~h}$. Subsequently, the remaining water on soil surface was eliminated by ear syringe.

\section{Sample Collection and Analyses}

Each treatment involved 24 replicates. Three replicates of each treatments were used to quantify $\mathrm{CO}_{2}$ and $\mathrm{CH}_{4}$ emission rates during 60-d incubation, and a silicone tube with a valve was placed on the empty upper part of those cores. During incubation, $\mathrm{CO}_{2}$ and $\mathrm{CH}_{4}$ emission rates were measured the day before and after each rewetting event. Each time, five $30 \mathrm{ml}$ chamber air samples were automatically pulled into air bags through a gas pump at $0,5,10,15$ and 20 min after closure. Next, they were transferred into $12 \mathrm{ml}$ pre-evacuated vials that were fitted using butyl rubber stoppers for the purpose of study. To balance the air pressure between outside and inside the PVC tube in sampling, the empty upper part of each core was equipped with a thin plastic air bag to connect with the outside via a tube. At the same time, the temperature of the chamber's air was measured using an automatic temperature recorder. With the use of a gas chromatograph (Agilent 7890, Santa Clara, CA, USA) coupled with a flame ionization detector, $\mathrm{CO}_{2}$ and $\mathrm{CH}_{4}$ concentrations were determined. In accordance with the repeated measurements of standard samples, the precisions of $\mathrm{CO}_{2}$ and $\mathrm{CH}_{4}$ levels were both $0.5 \%$. With the use of a linear least square fit to the five points in the time series of concentration for each soil core, $\mathrm{CO}_{2}$ and $\mathrm{CH}_{4}$ fluxes were calculated. Since $\mathrm{CO}_{2}$ and $\mathrm{CH}_{4}$ levels were determined every two or three days, their emission rates during sampling intervals were assumed to be equal to the average of the two emission rates from the two sampling events in the calculation of the average emission rates.

For soil physio-chemical properties, three replicates of each treatment were terminated at $0,6,16,31,46$, and $60-\mathrm{d}$ and 0 $10 \mathrm{~cm}$ soils were collected. Gravimetric water content was measured by oven drying fresh subsamples at $105^{\circ} \mathrm{C}$ until the dry weight was constant in a forced air oven. The remaining soil was air dried, crushed and stratified into two subsamples. One subsample was sieved through a $2-\mathrm{mm}$ sieve in order to test the soil $\mathrm{pH}$, salinity and texture, and the other was sieved through a $0.15-\mathrm{mm}$ mesh to determine the concentration of total carbon (TC), total nitrogen (TN), total organic carbon (TOC) and DOC. Soil salinity and $\mathrm{pH}$ were measured with an electricity conduction meter and a $\mathrm{pH}$ meter (soil: water $=1: 5)$, respectively. Using distilled water (1:5 soil water ratio), DOC in the soil was extracted and shaken for $1 \mathrm{~h}$ at ambient temperature, followed by centrifugation at $6000 \mathrm{rpm}$ for $25 \mathrm{~min}$. Then, the supernatant underwent filtering via a $0.45 \mu \mathrm{m}$ filter (Millipore Express). The concentration of DOC was measured with a TOC analyzer (TOC-VCPN, Shimadzu, Japan). In TOC analysis, for the removal of carbonates, this study gave the overnight treatment to soil samples using $1 \mathrm{~mol} \mathrm{~L}^{-1} \mathrm{HCL}$. After oven drying at $60^{\circ} \mathrm{C}$, the samples were ground to $0.15-\mathrm{mm}$ mesh underwent TOC analysis under the use of an element analyzer (Vario Micro cube, Elementar, Germany). Likewise, TC and TN were both measured with the element analyzer. With the use of a laser particle size analyzer (Marlvern Mastersizer 2000F, Malvern, UK), Grain size composition was studied. Subsequently, three categories were distinguished: $<2 \mu \mathrm{m}$ for clay, $2-20 \mu \mathrm{m}$ for silt and $>20 \mu \mathrm{m}$ for sand.

\section{Statistical Analysis}

To identify the differences in average emission rates of $\mathrm{CO}_{2}$ and $\mathrm{CH}_{4}$, DOC concentration, we performed one-way ANOVA analysis. $p<0.05$ was considered significant. Stepwise multiple regression and correlation analysis were performed to study the correlations of $\mathrm{CH}_{4}$ and $\mathrm{CO}_{2}$ emissions and DOC concentration with soil properties, and the correlations between soil properties. Statistics were studied using 
SPSS 19.0 (SPSS Inc., Chicago, IL, USA). Figures were drawn using Sigmaplot 12.5 (Systat Software Inc.).

\section{Results}

\section{Effects of Changes of Drying-Rewetting Frequency on $\mathrm{CO}_{2}$ and $\mathrm{CH}_{4}$ Emissions}

Increasing frequency of drying-rewetting cycles significantly decreased $\mathrm{CO}_{2}$ emission and increased $\mathrm{CH}_{4}$ emission (Fig. 1a and c). Drought produced significantly positive effect on $\mathrm{CO}_{2}$ emission but negative effect on $\mathrm{CH}_{4}$ emission. The average rates of $\mathrm{CO}_{2}$ emission before rewetting in all drying-rewetting treatments were significantly higher than those after rewetting (Fig. 1b). Furthermore, the differences between the average rates of $\mathrm{CO}_{2}$ emission before and after rewetting were higher in lower frequency drying-rewetting treatments. $\mathrm{CH}_{4}$ emission was induced by rewetting events. The average rates of $\mathrm{CH}_{4}$ emission before rewetting in all drying-rewetting treatments were significantly lower than those after rewetting (Fig. 1d). The difference between the average rates of $\mathrm{CH}_{4}$ emission before and after rewetting was $49.10 \mu \mathrm{g} \mathrm{CH}_{4}$ $\mathrm{m}^{-2} \mathrm{~h}^{-1}$ at 30D treatments, much higher than that at 5D and $15 \mathrm{D}$.

$\mathrm{CO}_{2}$ emission rates significantly increased with $\mathrm{TN}$ $(p<0.001)$, TOC $(p=0.001)$, sand fraction $(p=0.01)$ and salinity $(\mathrm{p}=0.01)$. In contrast, $\mathrm{CO}_{2}$ emission rates had a significant and negative correlation with gravimetric water content $(\mathrm{p}=0.001)$, silt fraction $(p=0.008)$ and clay fraction $(p=0.04)$, yet they were not dependent on $\mathrm{pH}, \mathrm{TC}$ and $\mathrm{C} / \mathrm{N}$ $(p>0.05)$. The stepwise multiple regressions (Table 3 ) showed that $\mathrm{CO}_{2}$ emissions were significantly impacted by DOC $(p<0.001)$, gravimetric water content $(\mathrm{p}<0.001)$ and TOC $(\mathrm{p}=0.01)$.

$\mathrm{CH}_{4}$ emission rates were strongly positively related to soil gravimetric water content $(\mathrm{p}<0.001), \mathrm{TC}(\mathrm{p}<0.001)$, TOC $(p<0.001), \mathrm{TN}(\mathrm{p}=0.001)$ and clay fraction $(p=0.04) . \mathrm{CH}_{4}$ emissions and salinity were found to be significantly negative related $(\mathrm{p}<0.001) . \mathrm{CH}_{4}$ emission rates were not correlated with some of the soil properties (e.g., $\mathrm{pH}, \mathrm{C} / \mathrm{N}$, silt fraction and sand fraction). According to the stepwise multiple regressions (Table 3 ), $\mathrm{CH}_{4}$ emissions were significantly impacted by gravimetric water content $(p<0.001)$ and TC $(\mathrm{p}<0.001)$.

\section{Effects of Changes of Drying-Rewetting Frequency on Soil DOC Formations}

At the end of incubation, significant differences in soil DOC concentration among all the treatments were observed (Fig. 2). Among the 3 drying-rewetting treatments, DOC concentration was lower in the drying-rewetting treatment with longer drying phase. Nevertheless, the lowest DOC concentration was $0.0156 \mathrm{mg} \mathrm{g}^{-1}$ in the $\mathrm{CM}$, and the highest reached $0.02 \mathrm{mg} \mathrm{g}^{-1}$ in the $\mathrm{CD}$.
Fig. 1 Cumulative $\mathrm{CO}_{2}$ (a) and $\mathrm{CH}_{4}(\mathbf{c})$ emissions under different treatments over the whole incubation period. Average soil gas emission rates before (solid bar) and after (empty bar) rewetting events under 5D, 15D and $30 \mathrm{D}$ treatments are also presented for $\mathrm{CO}_{2}$ (b) and $\mathrm{CH}_{4}$ (d). Bars and vertical lines represent means and SE. Letters represent significant differences between treatments at $p<0.05$. '**' indicates significant differences between the two conditions at $p<0.01$, ' $* * *$ ' indicates significant differences between the two conditions at $p<0.001$

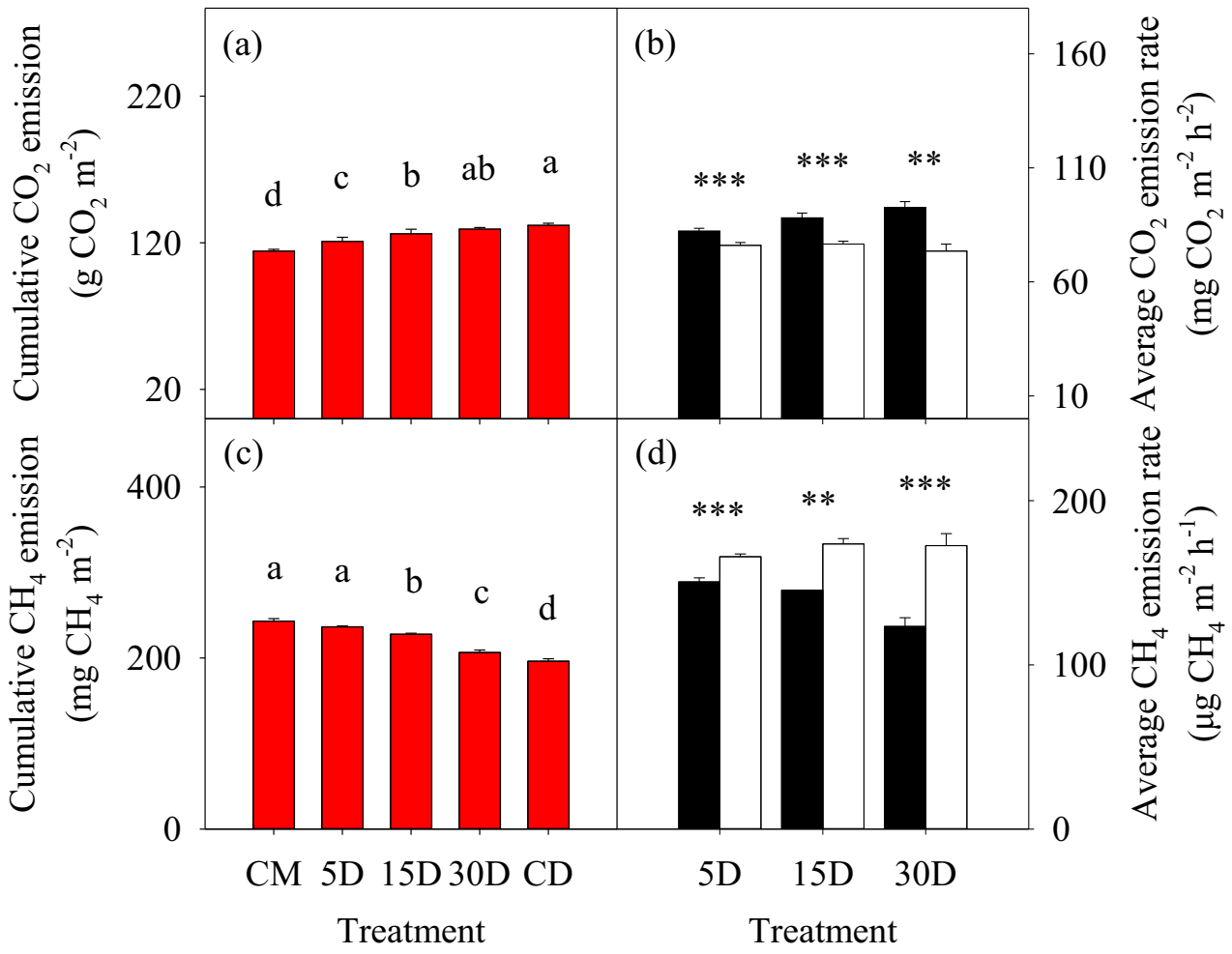




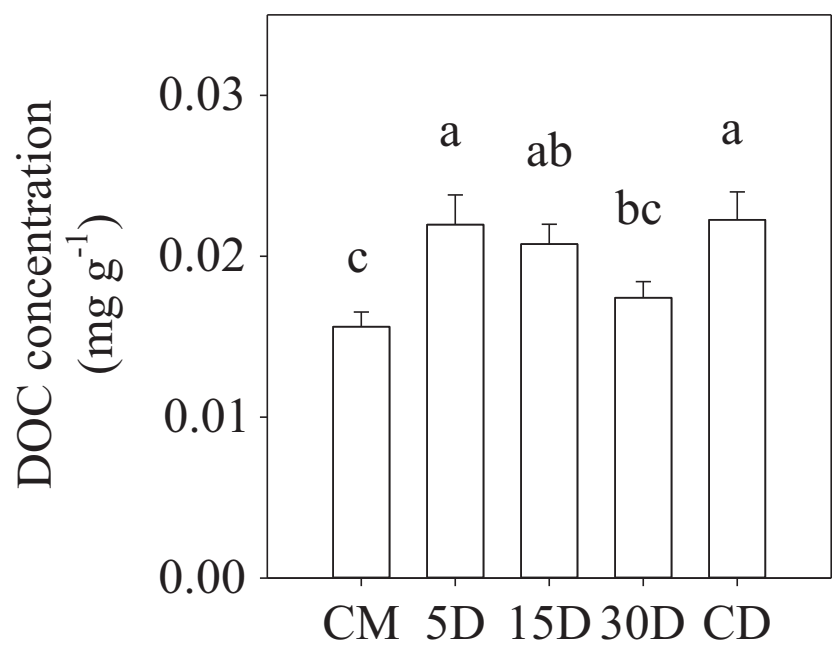

Treatments

Fig. 2 Average DOC concentrations at the end of incubation under different treatments. Bars and vertical lines represent means and SE. Letters represent significant differences between treatments at $p<0.05$

Based on the correlation analysis, soil DOC content was positively influenced by salinity, TOC, TC, TN and sand fraction, while it was negatively influenced by soil gravimetric water content, $\mathrm{pH}, \mathrm{C} / \mathrm{N}$ ratio, clay and silt fraction (Table 2). However, only TOC $(\mathrm{p}<0.001)$, TN $(\mathrm{p}<0.001), \mathrm{C} / \mathrm{N}$ ratio $(\mathrm{p}=0.04)$, clay $(p=0.02)$ and silt $(\mathrm{p}<0.001)$ content were significantly correlated with soil DOC concentration. The linear regressions indicated that soil DOC concentration was positively correlated with soil TOC and TN contents (Fig. 3). According to the stepwise multiple regressions (Table 3 ), DOC was significantly influenced by TN $(\mathrm{p}<0.001)$, TC $(p=0.002)$ and $\mathrm{pH}(p=0.02)$.

\section{Relationships between $\mathrm{CO}_{2}$ and $\mathrm{CH}_{4}$ Emissions Rates and DOC Concentrations under Different Drying-Rewetting Frequency}

For the determination of the impacts of $\mathrm{DOC}$ on soil $\mathrm{CO}_{2}$ and $\mathrm{CH}_{4}$ emissions, the regression analysis was performed (Fig. 4). According to the result, DOC had a close linear relation with soil $\mathrm{CO}_{2}$ emission rates $\left(\mathrm{r}^{2}=0.28, p<0.0001\right)$, while it was not closely correlated with soil $\mathrm{CH}_{4}$ emission rates here $(p>0.05)$. Besides, both the correlation analysis and the stepwise multiple regression showed that DOC was the most influential soil properties in the formation of $\mathrm{CO}_{2}$, while the result of the stepwise multiple regression suggested that DOC concentration and $\mathrm{CH}_{4}$ emission rates were not significantly correlated (Table 3 ).

\section{Effects of Changes in Drying-Rewetting Frequency on Soil Organic Carbon Loss}

The relationships of the cumulative $\mathrm{CO}_{2}$ and $\mathrm{CH}_{4}$ against soil gravimetric water content and salinity were examined to assess the influences of soil moisture and salinity on loss of soil vertical carbon loss (Fig. 5). Quadratic relationship was observed between cumulative $\mathrm{CO}_{2}$ emissions and soil moisture $\left(\mathrm{r}^{2}=0.95, p=0.05\right.$, Fig. 5a). Cumulative $\mathrm{CO}_{2}$ emissions increased with soil moisture before soil gravimetric water content reached $22 \%$ and then declined with the further increase in soil moisture. In addition, the linear regressions indicated that cumulative $\mathrm{CO}_{2}$ emissions were positively correlated with soil salinity $\left(\mathrm{r}^{2}=0.83, p=0.03\right.$, Fig. $\left.5 b\right)$. Cumulative $\mathrm{CH}_{4}$ emissions were increased with the increase of soil moisture $\left(r^{2}=0.98, p=0.02\right.$, Fig. $\left.5 c\right)$ while decreased linearly with soil salinity $\left(r^{2}=0.82, p=0.03\right.$, Fig. $\left.5 d\right)$.

Table 2 Correlation coefficients of $\mathrm{CO}_{2}$ emission rate, $\mathrm{CH}_{4}$ emission rate and DOC concentration with soil physio-chemical properties

\begin{tabular}{|c|c|c|c|c|c|c|c|c|c|c|c|c|c|}
\hline & $\mathrm{CO}_{2}$ & $\mathrm{CH}_{4}$ & DOC & $\begin{array}{l}\text { Gravimetric water } \\
\text { content }\end{array}$ & Salinity & $\mathrm{pH}$ & TOC & $\mathrm{TC}$ & $\mathrm{TN}$ & $\mathrm{C} / \mathrm{N}$ & Clay & Silt & Sand \\
\hline $\mathrm{CO}_{2}$ & 1 & & & & & & & & & & & & \\
\hline $\mathrm{CH}_{4}$ & -0.10 & 1 & & & & & & & & & & & \\
\hline DOC & $0.53^{* *}$ & 0.05 & 1 & & & & & & & & & & \\
\hline $\begin{array}{l}\text { Gravimetric water } \\
\text { content }\end{array}$ & $-0.34 * *$ & $0.49 * *$ & -0.12 & 1 & & & & & & & & & \\
\hline Salinity & $0.26^{*}$ & $-0.43 * *$ & 0.09 & $-0.68^{* *}$ & 1 & & & & & & & & \\
\hline $\mathrm{pH}$ & -0.06 & 0.12 & -0.12 & $0.31 * *$ & $-0.33^{* *}$ & 1 & & & & & & & \\
\hline TOC & $0.33^{* *}$ & $0.38 * *$ & $0.43 * *$ & $0.25^{*}$ & $-0.36^{* *}$ & 0.07 & 1 & & & & & & \\
\hline $\mathrm{TC}$ & 0.10 & $0.49 * *$ & 0.19 & $0.26^{*}$ & $-0.46^{* *}$ & 0.08 & $0.65 * *$ & 1 & & & & & \\
\hline $\mathrm{TN}$ & $0.37 * *$ & $0.35 * *$ & $0.60 * *$ & 0.12 & $-0.25^{*}$ & 0.12 & $0.80 * *$ & $0.64 * *$ & 1 & & & & \\
\hline $\mathrm{C} / \mathrm{N}$ & -0.04 & 0.13 & $-0.22 *$ & 0.27 & $-0.24 *$ & -0.02 & $-0.45 * *$ & 0.12 & -0.17 & 1 & & & \\
\hline Clay & $-0.21^{*}$ & $0.22 *$ & $-0.26^{*}$ & $0.38 * *$ & -0.15 & 0.02 & -0.06 & 0.03 & -0.17 & 0.17 & 1 & & \\
\hline Silt & $-0.28^{* *}$ & 0.13 & $-0.40 * *$ & $0.38 * *$ & -0.16 & 0.01 & -0.16 & -0.05 & $-0.33 * *$ & $0.24^{* *} *$ & $0.91 * *$ & 1 & \\
\hline Sand & $0.27^{*}$ & -0.14 & $0.38 * *$ & $-0.39 * *$ & 0.16 & -0.01 & 0.15 & 0.04 & $0.31 * *$ & $-0.23 * *$ & $-0.93 * *$ & $-0.99 * *$ & 1 \\
\hline
\end{tabular}

* Correlation is significant at the 0.05 level (2-tailed); ** Correlation is significant at the 0.01 level (2-tailed). DOC represents dissolved organic carbon, TOC represents total organic carbon, $T C$ represents total carbon, $T N$ represents total nitrogen 

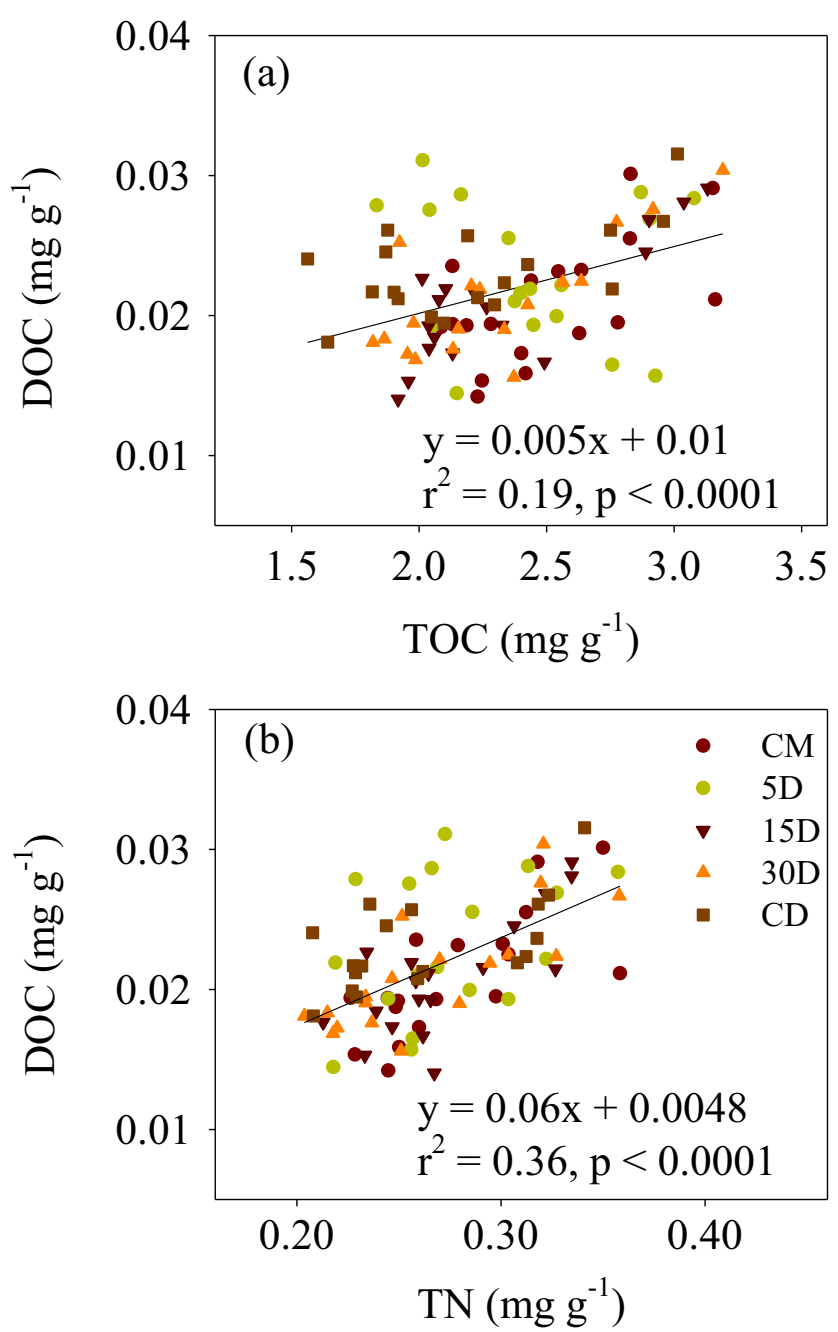

Fig. 3 Regressions of soil DOC concentrations $(n=90)$ with TOC (a), $\mathrm{TN}(\mathbf{b}), \mathrm{C} / \mathrm{N}$ (c) across the 60-d laboratory incubations. The scattered points represent data measured in each mesocosm

\section{Discussion}

\section{Effects of Drying-Rewetting Cycles on Soil Vertical Carbon Loss}

Soil vertical carbon loss was highly determined by soil moisture here. Obviously, average $\mathrm{CO}_{2}$ emissions over the treatment phase for soil with lower frequency of dryingrewetting cycles were much greater than those exposed to higher drying-rewetting cycles (Fig. 1a). An increase in water content exceeding the optimum value always led to the reduction in $\mathrm{CO}_{2}$ emissions because of the limited diffusion and oxygen stress (Jimenez et al. 2012; Malone et al. 2013). Previous studies performed in many other wetland ecosystems also showed very low $\mathrm{CO}_{2}$ emission rates after rewetting (Jimenez et al. 2012; Miao et al. 2017). During drying period, oxygen availability was promoted by deepening the depth of soil oxygenation and promoting gas diffusion, which further resulted in an increase in $\mathrm{CO}_{2}$ emission rates with the increase of metabolic activity of aerobic organisms (Malone et al. 2013; Webster et al. 2013; Olsson et al. 2015). Thus, the SOC loss in the form of $\mathrm{CO}_{2}$ in tidal salt marsh was strongly induced by the decrease of soil moisture with the decrease of frequency of dryingrewetting cycle (Fig. 5a). In contrast, under water saturation after rewetting, biological activity of methanogens was significantly boosted under anaerobic condition, which could lead to a rise of $\mathrm{CH}_{4}$ production (Kim et al. 2012; Webster et al. 2013). After rewetting, drying caused a decrease in $\mathrm{CH}_{4}$ emissions (Fig. 1d). Prior studies in wetland ecosystems has found that both rates of $\mathrm{CH}_{4}$ diffusion out of soil rates and oxidation rates increased when oxygenation went deeper (Malone et al. 2013; Olsson et al. 2015; Smith et al. 2018), which even made the soils a sink for $\mathrm{CH}_{4}$ (Bachoon and Jones 1992).

Besides, the results here showed that soil salinity had a strong negative correlation with $\mathrm{CH}_{4}$ emissions (Fig. 5d). However, this is contrary to $\mathrm{CO}_{2}$ (Fig. 5b). In general, salinity changes microbial community structure and has a strong negative impact on soil microbial activities, microbial biomass

Table 3 Stepwise multiple regression of $\mathrm{CO}_{2}, \mathrm{CH}_{4}$ emissions and DOC concentrations with soil physio-chemical properties

\begin{tabular}{|c|c|c|c|c|}
\hline & Variables entered and $p$ values & Regression equation & Multiple correlation coefficient & $\mathrm{F}$ and $p$ values \\
\hline $\mathrm{CO}_{2}$ & $\begin{array}{l}\text { 1. DOC, } p<0.001 \\
\text { 2. Gravimetric water content, } p<0.001 \\
\text { 3. TOC, } p=0.01\end{array}$ & $\begin{array}{l}\mathrm{CO}_{2}=0.38 \mathrm{DOC}-0.36 \mathrm{Gravimetric} \\
\quad \text { water content }+0.26 \mathrm{TOC}\end{array}$ & 0.64 & $20.01, p<0.001$ \\
\hline $\mathrm{CH}_{4}$ & $\begin{array}{l}\text { 1. Gravimetric content, } p<0.001 \\
\text { 2. TC, } p<0.001\end{array}$ & $\begin{array}{l}\mathrm{CH}_{4}=0.39 \text { Gravimetric } \\
\quad \text { water content }+0.39 \mathrm{TC}\end{array}$ & 0.62 & $26.51, \mathrm{p}<0.001$ \\
\hline DOC & $\begin{array}{l}\text { 1. } \mathrm{TN} \text { ratio, } \mathrm{p}<0.001 \\
\text { 2. } \mathrm{TC}, p=0.002 \\
\text { 3. } \mathrm{pH}, p=0.019\end{array}$ & $\mathrm{DOC}=0.82 \mathrm{TN}-0.33 \mathrm{TC}-0.192 \mathrm{pH}$ & 0.68 & $24.16, p<0.001$ \\
\hline
\end{tabular}

DOC represents dissolved organic carbon, TOC represents total organic carbon, TC represents total carbon 


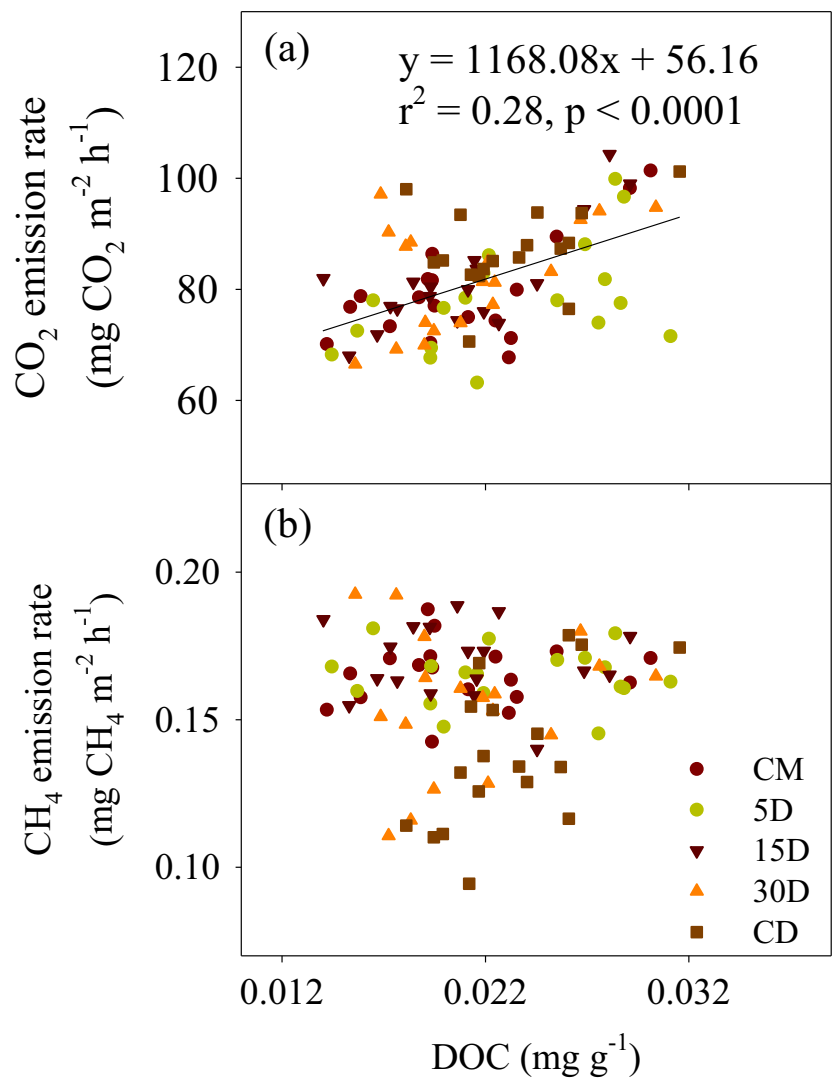

Fig. 4 Relationships of $\mathrm{CO}_{2}$ and $\mathrm{CH}_{4}$ emission rates $(n=90)$ with soil DOC concentrations across 60-d laboratory incubations. The scattered points represent data measured in each mesocosm

and enzyme activities (Chambers et al. 2013; Yan and Marschner 2013; Chambers et al. 2016). It further reduces the decomposition of SOC (Quintino et al. 2009; Poffenbarger et al. 2011). However, the correlation of $\mathrm{CO}_{2}$ production with soil salinity here was inconsistent with numerous studies, which found the increase in salinity followed by a suppression of $\mathrm{CO}_{2}$ production (Chambers et al. 2013). Soils with varying salinity caused by drying-rewetting cycles often differ in many other physio-chemical properties e.g., moisture content, texture and SOC content, which makes it hard to isolate the effect of salinity on soil $\mathrm{CO}_{2}$ production from that of other factors (Yan and Marschner 2013). A previous study demonstrated that soil respiration was highly determined by soil moisture at elevated soil salinities (Drake et al. 2014). Salinity of surface soil always varies with soil moisture content and increases as the moisture content decreases during long drying period (Yan and Marschner 2013). The results revealed that soil moisture content was more important in controlling the $\mathrm{CO}_{2}$ formations than salinity during drying-rewetting cycles, resulting in an overall rise of $\mathrm{CO}_{2}$ emissions along the increase in salinity.

Moreover, besides soil moisture and salinity, changes of many other physio-chemical properties induced by dryingrewetting cycles, e.g., SOC and nutrients content, also affect the soil vertical carbon loss by changing water retention, pore space and microbial activities (Harrison-Kirk et al. 2013; Moyano et al. 2013). It is generally accepted that production of $\mathrm{CO}_{2}$ and $\mathrm{CH}_{4}$ tends to increase with the increase of SOC content because of its critical role in substrate supply for microbes (Harrison-Kirk et al. 2014). Here, the highest rate of $\mathrm{CO}_{2}$ emission rate appeared in $\mathrm{CD}$ treatment at the end of the incubation because of reduction of moisture content, though the SOC content was relatively low (Data not shown). Hence, it seems to be more complex when describing the effect of SOC content on $\mathrm{CO}_{2}$ production under drying-rewetting cycles, while it was always considered a positive correlation between them at a fixed moisture value (Butterly et al. 2010; Harrison-Kirk et al. 2013).

\section{Effects of Drying-Rewetting Cycles on Soil Lateral Carbon Loss}

Soil DOC in coastal wetlands was always thought to be one of the main forms of lateral carbon loss from land to ocean through tidal export because of its high mobility (Fellman et al. 2017; Ray et al. 2018). Though soil DOC comprises only a small part of SOC, it has a significant impact on blue carbon pool in tidal salt marshes (Mavi and Marschner 2012; Barrón and Duarte 2016). Soil DOC concentration after 60-d incubation was highest in the CD treatment and lowest in the CM treatment (Fig. 2). This may be related to the following mechanisms. First, a previous study indicated that more DOC was released from drier soil (Gaelen et al. 2014). Second, there was no leaching or lateral export in $\mathrm{CD}$ treatment during incubation because of continuously drying. Moreover, soil DOC concentration after incubation was decreased with the frequency of drying-rewetting events (Fig. 2), which was probably because DOC produced in drying period was consumed by microbes after rewetting, as observed in other studies $(\mathrm{Wu}$ and Brookes 2005; Butterly et al. 2009). As a type of labile fraction of SOC, DOC generally decreased with the decrease in SOC, as reported in many field studies (McDonald et al. 2017; Zhao et al. 2018), which was also observed in our study.

\section{Contribution of $\mathrm{DOC}$ to $\mathrm{CO}_{2}$ and $\mathrm{CH}_{4}$ Formations}

A close linear relation between $\mathrm{CO}_{2}$ emission rates and $\mathrm{DOC}$ concentration has been observed here (Fig. 4a). The correlation coefficient between soil DOC and $\mathrm{CO}_{2}$ emission rates was strongly higher than that between soil TOC and $\mathrm{CO}_{2}$ rates (Table 2). Hence, it was concluded that DOC, the active part of SOC, was first utilized by microbes, and only a minor extent of $\mathrm{CO}_{2}$ came from the decomposition of the recalcitrant part according to the observations in some previous studies (Liu et al. 2017; Lee et al. 2018). In soil, dissolved organic matter is the most easily decomposable $\mathrm{C}$ source since soil microbes are almost aquatic and the availability of SOC 
determined by soil water environment (Marschner and Kalbitz 2003). However, many other studies found that significantly positive relationships between DOC concentrations and $\mathrm{CO}_{2}$ emissions can only be observed in the first few weeks of a long-term incubation, while it showed a decrease over time because of the depletion of DOC (Fellman et al. 2017; Qu et al. 2018). Furthermore, some previous study showed that $\mathrm{CO}_{2}$ emissions were also primarily determined by DOC bioavailability (Fellman et al. 2017; Liu et al. 2017), which deserves to be specially focused in further studies.

Compared to $\mathrm{CO}_{2}$ emissions, no association was observed here between DOC concentration and $\mathrm{CH}_{4}$ emission rates (Fig. 4b). Though it was always weaker than that of DOC and $\mathrm{CO}_{2}$, the positive relationship between DOC and $\mathrm{CH}_{4}$ was found in previous studies (Said-Pullicino et al. 2016; Liu et al. 2017). DOC could be exploited by methanogens under anaerobic conditions. However, a previous incubation found that the correlation curve of DOC and $\mathrm{CH}_{4}$ increased absolutely slow if the DOC concentration was low, while the curve increased sharply if the DOC concentration was high (Liu et al. 2017). Thus, one of the possible reason accounting for the results here might be the lack of DOC. For another, the critical reason for the inconsistency of results between our study and previous studies might be the changes of redox condition during drying-rewetting cycles since methane production requires a strictly anaerobic environment (Olsson et al. 2015).

\section{Limitation and Suggestions for Management}

By a laboratory experiment, this study determined the response of SOC losses to changed drying-rewetting frequency in tidal salt marshes. This method can limit the variability of other controlling factors, such as air temperature and SOC content. Furthermore, it is convenient to measure the gas emission rates at any time, which bring us the data resources with high time resolution. However, there are limitations and deficiencies in our study. On the one hand, this study only investigated the SOC loss but ignored the SOC input in a tidal salt marsh. In fact, it is crucial to considering the regulation of plants for revealing the mechanism of SOC loss (Duarte et al. 2013). On the other hand, microorganisms should be focused since they are play key role in the decomposition processes of SOC (Chambers et al. 2016). In the future, further studies need to be conducted on the mechanisms from the above two aspects.

The results of our study suggest that whether the frequency of soil drying-rewetting cycle increase or decrease, the carbon loss processes in tidal salt marsh would be severely disrupted. Based on present studies, the ability of salt marshes to build up
Fig. 5 Correlations of the cumulative $\mathrm{CO}_{2}$ and $\mathrm{CH}_{4}$ from each treatment with soil gravimetric water content and soil salinity during the 60-d incubations. Points were calculated as average values. Error bars represent standard deviation of replicates

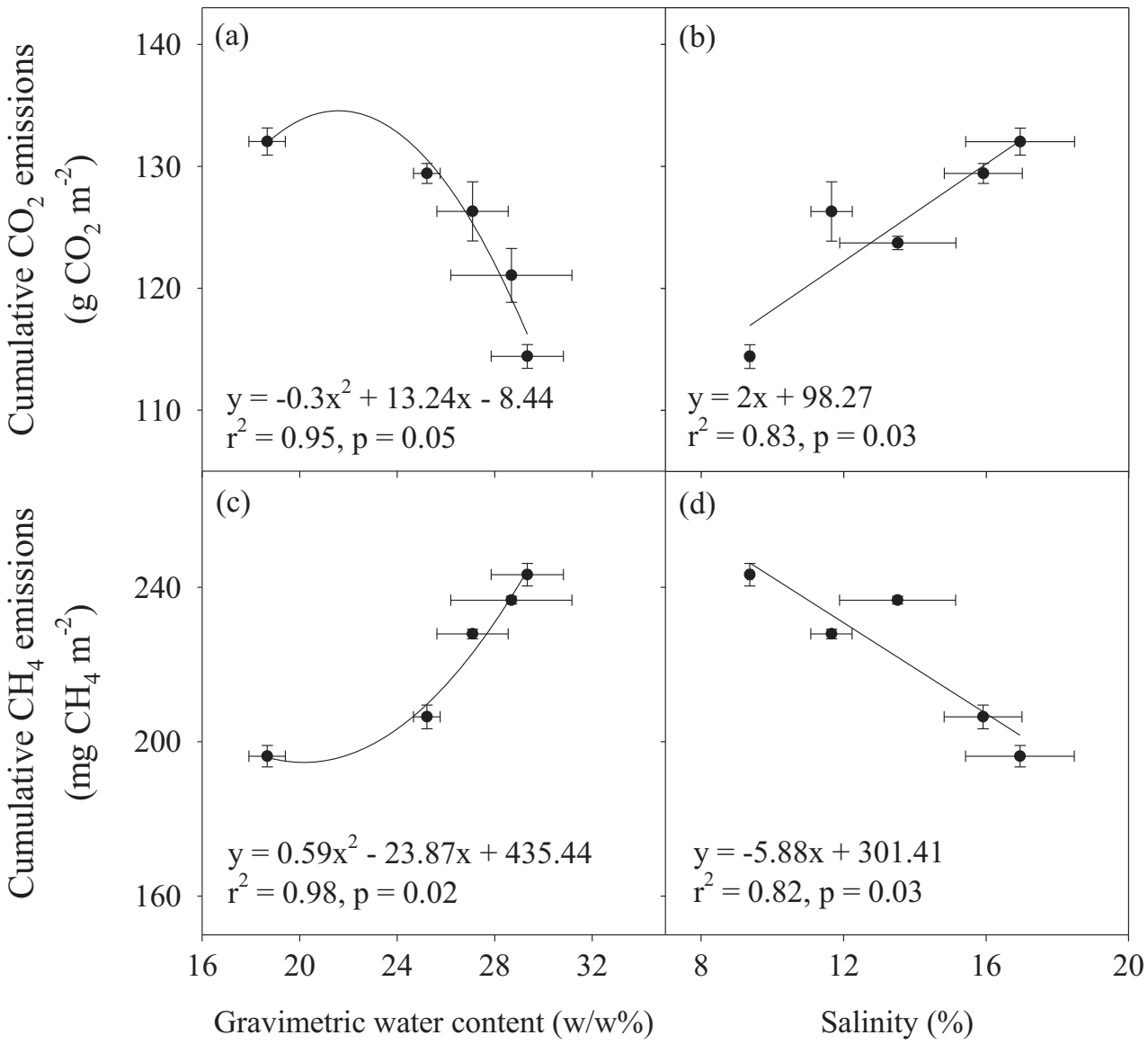


vertically by sediment accretion enable them to persist or even prosper with sea level rise (Schuerch et al. 2018; Kirwan and Megonigal 2013). In comparison, drying-rewetting process in tidal salt marshes is more strongly influenced by the building of anthropogenic infrastructure and invasion of exotic plants (Kirwan et al. 2016; Spencer et al. 2016). On the one hand, anthropogenic barriers (such as coastal flood protection structures and coastal roads) completely obstructed the tidal inundation and made large area of tidal salt marsh transferred into dry land (Schuerch et al. 2018). On the other hand, the great capacity of exotic invasion plants for mitigating erosion and trapping sediment will also lead to a sharp decrease of dryingrewetting frequency in tidal salt marshes (Zuo et al. 2012). Their induced ecological imbalance even loss of tidal salt marsh ecosystems is going to accelerate soil organic carbon loss. Thus, it is critical in keeping the stability and healthy of the tidal salt marsh ecosystems for achieving emission mitigation and sink enhancement of soil organic carbon through careful nature-based adaptation solutions.

\section{Conclusions}

Tidal salt marsh, a type of "blue carbon" sinks, plays a crucial part in global carbon sequestration. However, this important carbon pool is endangered by a series of natural or human disturbances, which will change the tidal actions as well as the drying-rewetting frequencies. On the whole, our findings suggested that the decrease in drying-rewetting frequency will increase the loss of SOC, which may convert tidal salt marsh from carbon sinks into carbon sources. To be specific, less frequent drying-rewetting cycles followed by more $\mathrm{CO}_{2}$ and less $\mathrm{CH}_{4}$ emissions in tidal salt marshes. Soil moisture, in a certain range, negatively affects $\mathrm{CO}_{2}$ emissions and positively affects $\mathrm{CH}_{4}$ emissions. Besides, soil lateral carbon loss was also significantly impacted by drying-rewetting frequency, as tidal salt marshes soil with high drying-rewetting frequency has high potential of DOC loss. According to our results, we suggested that the management should take adequate naturebased actions to ensure the stability and healthy of tidal salt marshes, thus reducing the soil organic carbon loss. Moreover, there is a significantly positive correlation between soil DOC concentration and $\mathrm{CO}_{2}$ emission rates. In the future, the effects of changes in drying-rewetting frequency on soil microbes in tidal salt marshes must be considered. Furthermore, it was found that vertical distribution of soil moisture and salt was being changed during drying-rewetting processes. Thus, future studies should also consider the effects of vertical migration of soil moisture and salinity on SOC decomposition during drying-rewetting processes.

Acknowledgements This work was founded by the National Nature Science Foundation of China (41671089), the Science and Technology
Service Network Initiative (KFJ-STS-ZDTP-023), Key deployment project of Chinese Academy of Sciences (KFZD-SW-112) and Strategic Priority Research Program of the Chinese Academy of Sciences (XDA23050202). We also thank Jianyang Xia, Guangmei Wang, Mingliang Zhao, Wenjun He and two anonymous reviewers of their expert advice and fruitful comments.

\section{References}

Bachoon D, Jones RD (1992) Potential rates of methanogenesis in sawgrass marshes with peat and marl soils in the Everglades. Soil Biology and Biochemistry 24(1):21-27

Barrón C, Duarte CM (2016) Dissolved organic carbon pools and export from the coastal ocean. Global Biogeochemical Cycles 29(10): $1725-1738$

Billett M, Charman D, Clark J, Evans C, Evans M, Ostle N, Worrall F, Burden A, Dinsmore K, Jones T (2010) Carbon balance of UK peatlands: current state of knowledge and future research challenges. Climate Research 45(1):13-29

Birch HF (1958) The effect of soil drying on humus decomposition and nitrogen availability. Plant and Soil 10(1):9-31

Butterly CR, Bünemann EK, Mcneill AM, Baldock JA, Marschner P (2009) Carbon pulses but not phosphorus pulses are related to decreases in microbial biomass during repeated drying and rewetting of soils. Soil Biology and Biochemistry 41(7):1406-1416

Butterly CR, Marschner P, Mcneill AM, Baldock JA (2010) Rewetting $\mathrm{CO}_{2}$ pulses in Australian agricultural soils and the influence of soil properties. Biology and Fertility of Soils 46(7):739-753

Chambers LG, Osborne TZ, Reddy KR (2013) Effect of salinity-altering pulsing events on soil organic carbon loss along an intertidal wetland gradient: a laboratory experiment. Biogeochemistry $115(1-3)$ : 363-383

Chambers LG, Guevara R, Boyer JN, Troxler TG, Davis SE (2016) Effects of salinity and inundation on microbial community structure and function in a mangrove peat soil. Wetlands 36(2):361-371

D'Amore DV, Edwards RT, Herendeen PA, Hood E, Fellman JB (2015) Dissolved organic carbon fluxes from hydropedologic units in alaskan coastal temperate rainforest watersheds. Soil Science Society of America Journal 79(2):378

Drake PL, Cormick CAMC, Smith MJ (2014) Controls of soil respiration in a salinity-affected ephemeral wetland. Geoderma 221:96-102

Duarte CM, Middelburg JJ, Caraco N (2005) Major role of marine vegetation on the oceanic carbon cycle. Biogeosciences 2(1):1-8

Duarte CM, Losada IJ, Hendriks IE, Mazarrasa I, Marbà N (2013) The role of coastal plant communities for climate change mitigation and adaptation. Nature Climate Change 3(11):961-968

Evans CD, Renou-Wilson F, Strack M (2015) The role of waterborne carbon in the greenhouse gas balance of drained and re-wetted peatlands. Aquatic Sciences 78(3):1-18

Fellman JB, D'Amore DV, Hood E, Cunningham P (2017) Vulnerability of wetland soil carbon stocks to climate warming in the perhumid coastal temperate rainforest. Biogeochemistry 133(2):165-179

Gaelen NV, Verschoren V, Clymans W, Poesen J, Govers G, Vanderborght J, Diels J (2014) Controls on dissolved organic carbon export through surface runoff from loamy agricultural soils. Geoderma 226:387-396

Han GX, Xing QH, Yu JB, Luo YQ, Li DJ, Yang LQ, Wang GM, Mao PL, Xie BH, Mikle N (2014) Agricultural reclamation effects on ecosystem $\mathrm{CO}_{2}$ exchange of a coastal wetland in the Yellow River Delta. Agriculture, Ecosystems and Environment 196:187-198

Harrison-Kirk T, Beare MH, Meenken ED, Condron LM (2013) Soil organic matter and texture affect responses to dry/wet cycles: effects on carbon dioxide and nitrous oxide emissions. Soil Biology and Biochemistry 57:43-55 
Harrison-Kirk T, Beare MH, Meenken ED, Condron LM (2014) Soil organic matter and texture affect responses to dry/wet cycles: changes in soil organic matter fractions and relationships with $\mathrm{C}$ and $\mathrm{N}$ mineralisation. Soil Biology and Biochemistry 74:50-60

Howard J, Sutton-Grier A, Herr D, Kleypas J, Landis E, McLeod E, Pidgeon E, Simpson S (2017) Clarifying the role of coastal and marine systems in climate mitigation. Frontiers in Ecology and the Environment 15(1):42-50

IPCC 2014 Climate Change (2014) Synthesis report. Environment Policy Collect 27:408

Jia J, Bai JH, Gao HF, Wen XJ, Zhang GL, Cui BS, Liu XH (2017) In situ soil net nitrogen mineralization in coastal salt marshes (Suaeda salsa) with different flooding periods in a Chinese estuary. Ecological Indicators 73:559-565

Jimenez KL, Starr G, Staudhammer CL, Schedlbauer JL, Loescher HW, Malone SL, Oberbauer SF (2012) Carbon dioxide exchange rates from short- and long-hydroperiod Everglades freshwater marsh. Journal of Geophysical Research - Biogeosciences 117:G04009

Kim DG, Vargas R, Bondlamberty B, Turetsky MR (2012) Effects of soil rewetting and thawing on soil gas fluxes: a review of current literature and suggestions for future research. Biogeosciences 9(7):24592483

Kirwan ML, Megonigal JP (2013) Tidal wetland stability in the face of human impacts and sea-level rise. Nature 504(7478):53-60

Kirwan ML, Temmerman S, Skeehan EE, Guntenspergen GR, Fagherazzi S (2016) Overestimation of marsh vulnerability to sea level rise. Nature Climate Change 6(3):253-260

Lee MH, Park JH, Matzner E (2018) Sustained production of dissolved organic carbon and nitrogen in forest floors during continuous leaching. Geoderma 310:163-169

Liu XJ, Ruecker A, Song B, Xing J, Conner WH, Chow AT (2017) Effects of salinity and wet-dry treatments on $\mathrm{C}$ and $\mathrm{N}$ dynamics in coastal-forested wetland soils: implications of sea level rise. Soil Biology and Biochemistry 112:56-67

Lovelock CE, Atwood T, Baldock J, Duarte CM, Hickey S, Lavery PS, Masque P, Macreadie PI, Ricart AM, Serrano O, Steven A (2017) Assessing the risk of carbon dioxide emissions from blue carbon ecosystems. Frontiers in Ecology and the Environment 15(5):257265

Macreadie PI, Nielsen DA, Kelleway JJ, Atwood TB, Seymour JR, Petrou K, Connolly RM, Thomson AC, Trevathan-Tackett SM, Ralph PJ (2017) Can we manage coastal ecosystems to sequester more blue carbon? Frontiers in Ecology and the Environment 15(4): 206-213

Maher DT, Santos IR, Golsby-Smith L, Gleeson J, Eyre BD (2013) Groundwater-derived dissolved inorganic and organic carbon exports from a mangrove tidal creek: the missing mangrove carbon sink? Limnology and Oceanography 58(2):475-488

Malone SL, Starr G, Staudhammer CL, Ryan MG (2013) Effects of simulated drought on the carbon balance of Everglades shorthydroperiod marsh. Global Change Biology 19(8):2511-2523

Marschner B, Kalbitz K (2003) Controls of bioavailability and biodegradability of dissolved organic matter in soils. Geoderma 113(3):211235

Mavi MS, Marschner P (2012) Drying and wetting in saline and salinesodic soils-effects on microbial activity, biomass and dissolved organic carbon. Plant and Soil 355(1-2):51-62

McDonald GK, Tavakkoli E, Cozzolino D, Banas K, Derrien M, Rengasamy P (2017) A survey of total and dissolved organic carbon in alkaline soils of southern Australia. Soil Research 55(7):617-629

McLeod E, Chmura GL, Bouillon S, Salm R, Bjork M, Duarte CM, Lovelock CE, Schlesinger WH, Silliman BR (2011) A blueprint for blue carbon: toward an improved understanding of the role of vegetated coastal habitats in sequestering $\mathrm{CO}_{2}$. Frontiers in Ecology and the Environment 9(10):552-560
Miao G, Noormets A, Domec JC, Fuentes M, Trettin CC, Sun G, Mcnulty SG, King JS (2017) Hydrology and microtopography control carbon dynamics in wetlands: implications in partitioning ecosystem respiration in a coastal plain forested wetland. Agricultural and Forest Meteorology 247:343-355

Morillas L, Durã NJ, Rodrã-Guez A, Roales J, Gallardo A, Lovett GM, Groffman PM (2015) Nitrogen supply modulates the effect of changes in drying-rewetting frequency on soil $\mathrm{C}$ and $\mathrm{N}$ cycling and greenhouse gas exchange. Global Change Biology 21(10): 3854-3863

Moyano FE, Manzoni S, Chenu C (2013) Responses of soil heterotrophic respiration to moisture availability: an exploration of processes and models. Soil Biology and Biochemistry 59:72-85

Olsson L, Ye S, Yu X, Wei M, Krauss KW, Brix H (2015) Factors influencing $\mathrm{CO}_{2}$ and $\mathrm{CH}_{4}$ emissions from coastal wetlands in the Liaohe Delta, Northeast China. Biogeosciences 12(4):4965-4977

Ouyang XG, Lee SY, Connolly RM (2017) The role of root decomposition in global mangrove and saltmarsh carbon budgets. Earth Science Reviews 166:53-63

Poffenbarger HJ, Needelman BA, Megonigal JP (2011) Salinity influence on methane emissions from tidal marshes. Wetlands 31(5):831-842

Qin Y, Yang ZF, Yang W (2010) A novel index system for assessing ecological risk under water stress in the Yellow River Delta Wetland. Procedia Environmental Sciences 2(6):535-541

Qu WD, Li JY, Han GX, Wu HT, Song WM, Zhang XS (2018) Effect of salinity on the decomposition of soil organic carbon in a tidal wetland. Journal of Soils and Sediments 19(2):609-617

Quintino V, Sangiorgio F, Ricardo F, Mamede R, Pires A, Freitas R, Rodrigues AM, Basset A (2009) In situ experimental study of reed leaf decomposition along a full salinity gradient. Estuarine, Coastal and Shelf Science 85(3):497-506

Ray R, Michaud E, Aller RC, Vantrepotte V, Gleixner G, Walcker R, Devesa J, Goff ML, Morvan S, Thouzeau G (2018) The sources and distribution of carbon (DOC, POC, DIC) in a mangrove dominated estuary (French Guiana, South America). Biogeochemistry 138(3):297-321

Said-Pullicino D, Miniotti EF, Sodano M, Bertora C, Lerda C, Chiaradia EA, Romani M, Maria SCD, Sacco D, Celi L (2016) Linking dissolved organic carbon cycling to organic carbon fluxes in rice paddies under different water management practices. Plant and Soil 401(1):273-290

Saviozzi A, Cardelli R, Puccio RD (2011) Impact of salinity on soil biological activities: a laboratory experiment. Communications in Soil Science and Plant Analysis 42(3):358-367

Schuerch M, Spencer T, Temmerman S, Kirwan ML, Wolff C, Lincke D, McOwen CJ, Pickering MD, Reef R, Vafeidis AT, Hinkel J, Nicholls RJ, Brown S (2018) Future response of global coastal wetlands to sea-level rise. Nature 561(7722):231-234

Smith KA, Ball T, Conen F, Dobbie KE, Massheder J, Rey A (2018) Exchange of greenhouse gases between soil and atmosphere: interactions of soil physical factors and biological processes. European Journal of Soil Science 69(4):10-20

Song Q, Zhang J, Cui T, Bao Y (2013) Retrieval of sea surface salinity with MERIS and MODIS data in the Bohai Sea. Remote Sensing of Environment 136:117-125

Spencer T, Schuerch M, Nicholls RJ, Hinkel J, Lincke D, Vafeidis AT, Reef R, McFadden L, Brown S (2016) Global coastal wetland change under sea-level rise and related stresses: the DIVA wetland change model. Global and Planetary Change 139:15-30

Tian B, Wu WT, Yang ZQ, Zhou YX (2016) Drivers, trends, and potential impacts of long-term coastal reclamation in China from 1985 to 2010. Estuarine, Coastal and Shelf Science 170:83-90

Webster KL, McLaughlin JW, Kim Y, Packalen MS, Li CS (2013) Modelling carbon dynamics and response to environmental change along a boreal fen nutrient gradient. Ecological Modelling 248(1751):148-164 
Wu J, Brookes PC (2005) The proportional mineralisation of microbial biomass and organic matter caused by air-drying and rewetting of a grassland soil. Soil Biology and Biochemistry 37(3):507-515

Xiang SR, Allen D, Patriciaa H, Joshuap S (2008) Drying and rewetting effects on $\mathrm{C}$ and $\mathrm{N}$ mineralization and microbial activity in surface and subsurface California grassland soils. Soil Biology and Biochemistry 40(9):2281-2289

Yan N, Marschner P (2013) Response of soil respiration and microbial biomass to changing EC in saline soils. Soil Biology and Biochemistry 65:322-328

Ye S, Laws EA, Yuknis N, Ding X, Yuan H, Zhao G, Wang J, Yu X, Pei S, Delaune RD (2016) Carbon sequestration and soil accretion in coastal wetland communities of the Yellow River Delta and Liaohe Delta, China. Estuaries and Coasts 39(6):294-294

Yemadje PL, Guibert H, Chevallier T, Deleporte P, Bernoux M (2016) Effect of biomass management regimes and wetting-drying cycles on soil carbon mineralization in a Sudano-Sahelian region. Journal of Arid Environments 127:1-6

Yuan JJ, Ding WX, Liu DY, Kang H, Freeman C, Xiang J, Lin YX (2015) Exotic Spartina alterniflora invasion alters ecosystem-atmosphere exchange of $\mathrm{CH}_{4}$ and $\mathrm{N}_{2} \mathrm{O}$ and carbon sequestration in a coastal salt marsh in China. Global Change Biology 21(4):1567-1580

Zhao QQ, Bai JH, Zhang GL, Jia J, Wang W, Wang X (2018) Effects of water and salinity regulation measures on soil carbon sequestration in coastal wetlands of the Yellow River Delta. Geoderma 319:219 229

Zuo P, Zhao S, Liu C, Wang CH, Zhao YB (2012) Distribution of Spartina spp. along China's coast. Ecological Engineering 40:160 166

Publisher's Note Springer Nature remains neutral with regard to jurisdictional claims in published maps and institutional affiliations. 